\title{
GRUPOTERAPIA COGNITIVO-COMPORTAMENTAL PARA MENINAS VÍTIMAS DE ABUSO SEXUAL: DESCRIÇÃO DE UM MODELO DE INTERVENÇÃO ${ }^{1}$
}

\author{
Luisa F. Habigzang* \\ Roberta Hatzenberger** \\ Fabiana Dala Corte*** \\ Fernanda Stroeher**** \\ Silvia Koller****
}

\section{RESUMO}

O abuso sexual contra crianças e adolescentes é uma forma de violência que pode desencadear disfunçôes cognitivas, emocionais e comportamentais que necessitam intervenção psicológica. $\mathrm{O}$ tratamento das vítimas e suas famílias é um desafio para a prática de psicólogos, devido à complexidade do fenômeno. O presente trabalho tem como objetivo descrever um processo de grupoterapia cognitivo-comportamental desenvolvido para casos de abuso sexual. As técnicas utilizadas são apresentadas a partir da experiência das autoras em uma pesquisa que objetivou avaliar a efetividade deste modelo. Participaram do estudo 10 meninas vítimas de abuso sexual intrafamiliar com idade entre 9 e 13 anos. Os resultados apontaram que o processo de grupoterapia contribui para a reestruturação de crenças, reaçōes emocionais e comportamentais disfuncionais. $\mathrm{O}$ grupo representou um elo na rede de apoio social e afetiva das meninas e promoveu melhoras na qualidade de vida.

Palavras-chave: abuso sexual, terapia cognitivo-comportamental, infância, adolescência

* Psicóloga, Mestre e Doutoranda em Psicologia pela Universidade Federal do Rio Grande do Sul; membro do CEP-RUA.

** Psicóloga e membro do CEP-RUA / Universidade Federal do Rio Grande do Sul.

*** Psicóloga e membro do CEP-RUA / Universidade Federal do Rio Grande do Sul.

**** Psicóloga e membro do CEP-RUA / Universidade Federal do Rio Grande do Sul.

***** Psicóloga; doutora em Educação pela PUCRS; professora do Programa de Pós-Graduação em Psicologia da UFRGS e pesquisadora do CNPq e coordenadora do CEP-RUA / Instituto de Psicologia / UFRGS. 


\begin{abstract}
COGNITIVE-BEHAVIOURAL GROUP THERAPY FOR SEXUAL ABUSED GIRLS: DESCRIPTION OF AN INTERVENTION MODEL

The sexual abuse against children and adolescents is a violence form that can unchain cognitive, emotional, and behavioural dysfunctions that will need psychological intervention. The victim' and families' treatment are a challenge for the psychologists' practice, due to the complexity of the phenomenon. The present study aims to describe a cognitive behavioral group therapy process developed for cases of sexual abuse. The techniques are based on previous experiences in a research that aimed at to evaluate the effectiveness of the model. Ten 9 to 13 year old girls, victims of intrafamilial sexual abuse participate in the study. The results pointed out to the contribution of the group therapy process to the restructuring of faiths, emotional reactions, and behavioral dysfunctions. The group represented a link in the girls' social and emotional support network and improved their life quality.

Keywords: sexual abuse, cognitive-behavior therapy, childhood, adolescence
\end{abstract}

\title{
1. INTRODUÇÃo
}

O abuso sexual contra crianças e adolescentes é definido como o envolvimento de uma criança ou adolescente em atividade sexual que essa não compreende totalmente, para a qual é incapaz de dar consentimento, ou não está preparada devido ao estágio de desenvolvimento. $\mathrm{O}$ abuso sexual viola as leis ou tabus da sociedade e se expressa em qualquer atividade entre uma criança e um adulto ou outra criança que, pela idade ou estágio do desenvolvimento, está em uma relação de responsabilidade, confiança ou poder. A atividade sexual é destinada para gratificação ou satisfação das necessidades desta outra pessoa. Isto pode incluir, mas não se limita, a indução ou coerção de uma criança para engajar-se em qualquer atividade sexual, a exploração de uma criança em sexo comercial ou outra prática sexual ilegal, o uso de crianças em performances ou materiais pornográficos (Organização Mundial da Saúde, 1999).

As conseqüências do abuso sexual para crianças ou adolescentes podem incluir o desenvolvimento de transtornos psicológicos do humor, de ansiedade, alimentares, enurese, encoprese, transtornos dissociativos, hiperatividade e déficit de atenção e transtorno do estresse pós-traumático (Briere e Elliott, 2003; Cohen, Mannarino e Rogal, 2001; Habigzang e Caminha, 2004; Heflin e Deblinger, 1996/ 1999; Runyon e Kenny, 2002). Entretanto, o transtorno do estresse pós-traumático (TEPT) é a psicopatologia mais citada como decorrente do abuso sexual e é estimado que $50 \%$ das crianças que foram vítimas desta forma de violência desenvolvem sintomas (Cohen, 2003). 
Além de transtornos psicológicos, crianças e adolescentes vítimas de abuso sexual podem apresentar alterações comportamentais, cognitivas e emocionais. Entre as alteraçôes comportamentais destacam-se: conduta hipersexualizada, abuso de substâncias, fugas do lar, furtos, isolamento social, agressividade, mudanças nos padrões de sono e alimentação, comportamentos autodestrutivos, tais como se machucar e tentativas de suicídio. As alterações cognitivas incluem: baixa concentração e atenção, dissociação, refúgio na fantasia, baixo rendimento escolar e crenças distorcidas, tais como percepção de que é culpada pelo abuso, diferença em relação aos pares, desconfiança e percepção de inferioridade e inadequação. As alterações emocionais referem-se aos sentimentos de medo, vergonha, culpa, ansiedade, tristeza, raiva e irritabilidade (Cohen e Mannarino, 2000; Cohen, Mannarino e Rogal, 2001; Habigzang e Caminha, 2004; Haugaard, 2003; Jonzon e Lindblad, 2004; Rosenthal, Feiring, e Taska, 2003).

Dentre as abordagens de intervenção psicológicas, a terapia cognitivo-comportamental (TCC) vem sendo testada por diversos pesquisadores (Astin e Resick, 2002; Calhoun e Resick, 1993/1999; Celano, Hazzard, Campbell e Lang, 2002; Cohen, 2003; Saywitz, Mannarino, Berliner e Cohen, 2000) como método de intervenção para casos de abuso sexual infantil, tanto individualmente quanto no formato de grupo. Uma das razões pelas quais a TCC é potencialmente benéfica nestes casos é por incorporar no tratamento estratégias que têm como alvos sintomas específicos. As intervençóes têm como alvos, principalmente, sintomas de TEPT (revivência do evento traumático com pensamentos ou flashbacks, esquiva de lembranças e excitação aumentada). A ansiedade e esquiva são trabalhadas com exposição gradual e dessensibilização sistemática, inoculação de estresse, treino de relaxamento e interrupção e substituição de pensamentos perturbadores por outros que recuperem o controle das emoções. Sintomas de depressão são trabalhados com treino de habilidades de coping e reestruturação de cognições distorcidas. Problemas comportamentais são trabalhados com técnicas de modificação de comportamento. Além disso, a TCC trabalha na prevenção de futuras revitimizações. Considerando as conseqüências negativas do abuso sexual para o desenvolvimento psicológico das vítimas, bem como os resultados positivos da terapia cognitivo-comportamental para redução de sintomas e reestruturação da memória traumática, o presente trabalho tem como objetivos descrever um modelo de grupoterapia cognitivo-comportamental para meninas vítimas de abuso sexual, bem como a avaliar e discutir o processo terapêutico. $\mathrm{O}$ modelo de intervenção descrito é uma adaptação da proposta de Habigzang e Caminha (2004). 


\section{Metodologia}

\subsection{PARTICIPANTES}

O estudo foi realizado com 10 meninas com idade entre nove e 13 anos que foram submetidas a pelo menos um episódio de abuso sexual intrafamiliar. As meninas foram encaminhadas pelo Conselho Tutelar, Programa Sentinela e Programa de Apoio a Meninos e Meninas (PROAME). Os critérios de inclusão para o estudo foram: presença de pelo menos um episódio de abuso sexual intrafamiliar, sexo e idade. Os critérios de exclusão foram presença de sintomas psicóticos e retardo mental graves. Contudo, não houve encaminhamento de meninas com tais características.

\subsection{PROCEDIMENTOS}

Inicialmente o projeto desta pesquisa foi avaliado e aprovado pelo Comitê de Ética da Universidade Federal do Rio Grande do Sul. Após a aprovação, foi realizado o treinamento teórico-metodológico e ético da equipe que auxiliou na pesquisa. Em seguida, o contato com o Conselho Tutelar e o Programa Sentinela foi estabelecido para os encaminhamentos. Outros órgãos, tais como abrigos, Promotoria da Infância e Juventude, PROAME e Secretaria da Educação foram visitados pela equipe para a divulgação da pesquisa.

As meninas encaminhadas foram convidadas para uma entrevista inicial, na qual foram consultadas quanto à participação na pesquisa, sendo incluídas na amostra mediante o seu consentimento livre e esclarecido (TCLE). Além das meninas, os cuidadores não-abusivos responsáveis também foram consultados sobre a participação dessas no estudo. É importante salientar que todas as meninas estavam protegidas de abusos sexuais durante o estudo. $\mathrm{O}$ caso no qual a menina ainda estava em risco foi denunciado pela equipe de pesquisa aos órgãos de proteção à Criança e ao Adolescente para que as medidas necessárias fossem efetivadas (Art. 13, Lei Federal n 8069/ 1990, Estatuto da Criança e do Adolescente, 1990). A denúncia foi seguida do acompanhamento do caso junto ao Conselho pela equipe.

Antes da inserção no grupo, as meninas foram avaliadas clinicamente em três encontros individuais. A avaliação teve como objetivos conhecer a história de abuso sexual, identificar fatores de risco e proteção relacionados às meninas e às suas famílias, investigar sintomas de depressão, ansiedade, TEPT e crenças disfuncionais relacionadas ao abuso (autores deste texto, submetido). 
Após a avaliação clínica individual, as participantes foram encaminhadas para a intervenção grupoterápica. $\mathrm{O}$ modelo de intervenção grupal cognitivocomportamental descrito é uma adaptação do modelo proposto por Habigzang e Caminha (2004). A adaptação do modelo original foi em relação à ordem das sessões e à reestruturação das etapas do processo grupoterápico. Além disso, houve alterações em alguns dispositivos de intervenção. A grupoterapia foi composta por 20 sessões com freqüência semanal. As sessões tiveram atividades semiestruturadas, com duração de uma hora e trinta minutos. Os objetivos da intervenção foram: reestruturar pensamentos, emoções e comportamentos disfuncionais relacionados à experiência de violência sexual; reduzir sintomas de transtorno do estresse pós-traumático, depressão e ansiedade; e aprender habilidades de autoproteção para prevenir futuras revitimizações. O processo grupoterápico foi dividido em três etapas conforme as técnicas empregadas: Etapa 1 - Psicoeducação (sete sessões); Etapa 2 - Treino de inoculação do estresse (cinco sessões); e Etapa 3 - Prevenção à recaída (oito sessões).

\section{Resultados e discussão}

Todas as meninas permaneceram em atendimento pela equipe de pesquisa até a conclusão do processo terapêutico. A assiduidade das participantes foi satisfatória ( $90 \%$ das sessōes) e verificou-se o engajamento de todas no processo, bem como o estabelecimento de um forte vínculo terapêutico com as psicoterapeutas. A assiduidade e a permanência das participantes durante todo o processo é um resultado positivo desta intervenção com a equipe de pesquisa, pois altos índices de perda de participantes são verificados em pesquisas sobre psicoterapia para crianças vítimas de abuso sexual (Cohen, Mannarino e Knudsen, 2005; Deblinger, Stauffer e Steer, 2001; Horowitz, Putnam, Noll e Trickett, 1997).

Cada grupo foi constituído por cinco participantes, conforme o turno no qual estavam matriculadas na escola. No grupo da manhã, a idade das participantes variou entre nove e 11 anos, sendo composto por Paula, Cristiane, Juliana, Andréia e Fernanda ${ }^{2}$.

Neste grupo apenas Paula estava abrigada, enquanto as demais residiam com familiares. O grupo da tarde apresentava características diferentes, uma vez que apenas Daniela residia com a família e as demais estavam abrigadas no mesmo local. A idade das participantes do grupo da tarde concentrou-se entre os onze e treze anos e foi formado por Priscila, Luciana, Mariana, Daniela e Elisa. A coesão, ou seja, a atração e o estabelecimento de uma relação de apoio e de aceitação entre as participantes de cada grupo ocorreu facilmente já nos primeiros encontros. 
Contudo, no grupo da manhã foram verificadas diferentes demandas conforme a faixa etária, pois as meninas mais velhas já apresentavam questôes relacionadas à adolescência, tais como o ficar e namorar. Essas diferenças foram acolhidas e trabalhadas no contexto grupal e não impediram o vínculo entre as participantes.

O processo terapêutico foi dividido em três etapas: psicoeducação, treino de inoculação do estresse e prevenção à recaída. As sete sessões de psicoeducação tiveram como foco desenvolver a confiança entre os membros do grupo, estabelecer as metas terapêuticas, discutir o que é abuso sexual, como este ocorre e quais são as conseqüências para as vítimas e as famílias, compartilhar o modelo cognitivocomportamental, mapeando pensamentos, emoções e comportamentos relacionados ao abuso e à percepção de si, do perpetrador e das mudanças na configuração familiar.

$\mathrm{Na}$ primeira sessão as terapeutas propuseram uma dinâmica de apresentação para ambos os grupos, na qual as meninas entrevistaram umas às outras, em duplas e trios, e depois cada participante apresentou ao grupo a menina que havia entrevistado. As meninas enfocaram em suas entrevistas a idade, série, escola, atividades e programas de televisão favoritos, esportes que praticavam, com quem residiam, etc. Após a dinâmica de apresentação, as terapeutas exploraram as expectativas com relação aos próximos encontros. As meninas construíram um painel, no qual escreveram suas expectativas. As principais expectativas foram: conversar sobre o abuso, desabafar, fazer novas amizades e entender por que pessoas de quem gostavam abusaram delas. Durante a confecção dos cartazes, as meninas conversaram sobre novelas, escola e família. Elas fizeram desenhos umas das outras e colocaram seus nomes no painel. A partir das expectativas mapeadas pelas participantes, as terapeutas explicaram que o grupo seria um espaço seguro, no qual poderiam conversar sobre a experiência de abuso sexual e construir formas de lidar com as conseqüências dessa experiência. O grupo da tarde escolheu o nome "grupo da vida" para identificarem-se, enquanto o grupo da manhã não chegou a um consenso e não quiseram colocar nome em seu grupo. $\mathrm{O}$ contrato terapêutico foi retomado no primeiro encontro, mesmo tendo sido proposto no final da avaliação inicial, sendo que o número de sessões, horário e importância de comparecer a todas as sessões foram reforçadas.

A segunda sessão iniciou com a dinâmica "caminhada em confiança” (Smith, 1993/1996), que teve como objetivo desenvolver a confiança entre as participantes de ambos os grupos. As meninas dividiram-se em duplas e uma delas formou grupo com a co-coordenadora. Em seguida, uma menina de cada dupla vendou os olhos e a outra a conduziu em uma caminhada. Depois os papéis foram invertidos. As meninas demonstraram muito cuidado na condução de quem estava 
vendada. Cristiane pegou Paula no colo para que não caísse nas escadas. As meninas divertiram-se durante a dinâmica e depois contaram no grupo como se sentiram durante a brincadeira. Mariana disse que é difícil não enxergar, mas que não ficou com medo de ser conduzida por Priscila. Juliana disse sentir-se responsável por Fernanda, enquanto esta não enxergava. Depois de explorar as percepções das meninas, as coordenadoras reforçaram a idéia de que o grupo constituía um espaço seguro para expor situações da vida delas e convidaram as participantes a relatar o que havia acontecido em suas famílias e que as tinha levado a participar da intervenção. As meninas compartilharam com o grupo as experiências sexualmente abusivas com maior facilidade e detalhes do que na entrevista inicial. Este fato pode ter tido relação com a função da universalidade, ou seja, a percepção que o formato grupal lhes propiciava de não estarem sozinhas frente ao problema, mas que existiam outras pessoas que experienciaram problemas semelhantes (Sheldon, 1993/1996). As participantes identificaram semelhanças e diferenças entre suas experiências e perguntaram sobre abuso sexual, estupro e o que acontece com os adultos que cometem estas formas de violência. As coordenadoras explicaram para as meninas o que é abuso sexual e estupro e informaram que isto é um crime e que os adultos agressores devem responder judicialmente por este crime. Contudo, salientaram as dificuldades do sistema judiciário para efetivar a lei. No grupo de Cristiane (nove anos), ela, então, contou que seus padrinhos foram presos e quis saber o que aconteceu com os demais agressores. Ao saber que nenhum havia sido preso, Cristiane ficou indignada, dizendo "não acredito, isso é muito injusto, eles deveriam ficar presos para sempre". As coordenadoras, ao perceberem algum sentimento de culpa em algumas meninas, perguntaram diretamente se elas sentiam culpa pelo que aconteceu e, com exceção de Mariana, que disse firmemente que seu pai era culpado, as demais meninas manifestaram sentir culpa por não terem contado logo a violência que estavam sofrendo. No final da sessão de ambos os grupos, as terapeutas questionaram como as meninas estavam se sentindo após a revelação da experiência de abuso e estas apontaram que se sentiam aliviadas por contar o ocorrido e perceber que outras meninas passaram por situações semelhantes.

A terceira sessão teve como objetivo abordar as reações da família e demais pessoas significativas depois da revelação e construir um mapeamento das possíveis mudanças na configuração familiar em ambos os grupos. A confecção do livro "Minha família antes e depois" foi utilizada como dispositivo para as meninas expressarem as mudanças na configuração familiar. As principais conseqüências foram o afastamento entre os familiares e o abrigamento de algumas participantes. O relato a seguir ilustra as mudanças na família: 
Antes, todo domingo nós freqüentávamos a casa do meu dindo e toda nossa família comia churrasco e era meu dindo que fazia. Eu lembro que os vizinhos comentavam como nossa família era unida. Ele era meu dindo predileto e sempre me dava bastante presentes. Eu ia lá todo dia, eles moravam bem pertinho da minha casa. Depois que eu contei para minha mãe, ela chorou muito porque sempre que nós precisávamos de alguma coisa, ou até dinheiro, ele emprestava e agora não tem mais isso. Acabou o churrasco na casa dele e minha mãe não deixa eu nem chegar perto dele, muito menos ir na casa dele (Andréia, 11 anos).

Considerando o relato dessa participante, ficam evidentes fatores da dinâmica do abuso, tais como: as barganhas do abusador, os sentimentos ambivalentes da criança em relação ao abusador e o sentimento de culpa da vítima pela desorganização familiar que têm sido citados também na literatura sobre o tema (Furniss, 1993; Gabel, 1997).

A percepção de culpa apontada pelas participantes em sessão anterior foi retomada no terceiro encontro. As meninas perceberam que mantiveram a situação em segredo por medo das ameaças sofridas, das brigas na família e de não acreditarem nelas. Daniela (12 anos) disse: "não me sinto tão culpada porque eu só tinha cinco anos e não entendia o que estava acontecendo, mas ele era adulto e sabia o que estava fazendo".

A quarta sessão teve como objetivos iniciar a psicoeducação quanto ao modelo cognitivo-comportamental, no qual o enfoque foi aprender a identificar diferentes estados emocionais e, depois, explorar os sentimentos das meninas com relação ao agressor. $\mathrm{O}$ jogo "o que são emoçôes" foi utilizado como dispositivo para a psicoeducação. Nesse jogo, as meninas relacionavam situações cotidianas com reaçôes emocionais. Um painel com afirmaçôes que retratavam situaçôes agradáveis e desagradáveis, tais como "ganhei um presente", "fui convidada para a festa da minha amiga", "tirei nota baixa na escola", "briguei com alguém de quem gosto muito", "lembrei do abuso" foi apresentado para as meninas e cartôes com bonecos com diferentes expressōes emocionais foram distribuídos. As meninas liam a afirmação e escolhiam o cartão que correspondia à emoção que sentiriam em tal situação. As meninas identificaram com facilidade as emoções em ambos os grupos.

Depois do jogo sobre emoçôes, as terapeutas sugeriram conversar sobre o que as participantes sentiam em relação aos agressores. Tais sentimentos foram abordados no grupo através de uma técnica pela qual as meninas construíram o agressor com massa de modelar. Depois da construção por cada menina houve, um espaço para que dissessem ao agressor tudo o que pensavam e sentiam sobre o 
abuso sexual que haviam sofrido. A maioria das meninas falou sobre a decepção, pois gostavam e confiavam neles e na raiva que sentiam pelo que fizeram. Depois do role-play com o boneco de massa, foi informado às meninas que elas podiam fazer o que quisessem com este. Com exceção de Fernanda (10 anos), que quis levar o boneco (que representava seu irmão) para casa, dizendo que iria cuidar dele para não estragar, todas as demais meninas destruíram o boneco, externalizando sentimento de raiva. No final deste encontro, as meninas receberam um automonitoramento como tarefa de casa, no qual deveriam registrar situações importantes da semana e a emoção que tivessem em tais situaçôes.

A quinta sessão teve como objetivo psicoeducar os grupos para identificar pensamentos em relação ao abuso e compreender a relação existente entre situação, emoção e pensamento. $\mathrm{O}$ automonitoramento realizado pelas meninas como tarefa de casa foi utilizado como dispositivo para o jogo "detetive de pensamentos". Cada menina leu as situações que havia registrado no monitoramento e a emoção correspondente. Depois as terapeutas explicaram que os pensamentos são idéias, imagens, lembranças que passam pela cabeça e que estão relacionadas com as emoções. Em seguida, as meninas foram convidadas a brincar que eram detetives de pensamentos e foram desafiadas a tentar descobrir os pensamentos que estavam relacionados com as situações e as emoções que haviam registrado no automonitoramento.

Os pensamentos das meninas sobre o abuso foram mapeados e apareceram crenças distorcidas sobre si mesmas e sobre o abuso, tais como a atribuição de culpa pelo abuso e pelos conflitos familiares decorrentes da revelação. Outras crenças distorcidas identificadas foram as idéias de que são diferentes de outras meninas da mesma idade e de que devem elas desconfiar de todos os homens que se aproximam delas. As meninas, ainda, apontaram que as pessoas sabem que elas foram vítimas de abuso sexual pela aparência. No grupo da tarde, por exemplo, Priscila (13 anos) disse: "Quando saio na rua sei que as pessoas olham para mim e sabem que fui abusada”. Daniela (12 anos), então, completou: "As pessoas não tem como saber disso se não contarmos, quer ver?", e levantou-se, convidando Priscila a encenar uma situação. Continuou: "Vamos fazer de conta que nunca nos vimos e nem conversamos e estamos passeando na rua e nos cruzamos". Elas passaram uma pela outra e ficaram se olhando. Daniela perguntou: "Tu achas que saberias que eu fui vítima de abuso?”; e Priscila logo respondeu que não. Então, Daniela concluiu: "Isso serve para ti também, as pessoas não têm como saber isso só olhando para a gente". A situação encenada flexibilizou a crença disfuncional, permitindo que a menina considerasse a explicação alternativa proposta pela outra.

As distorções cognitivas das vítimas em relação ao evento abusivo têm sido apontadas atualmente pela literatura especializada como desencadeadoras e 
mantenedoras de sintomas psicopatológicos. Tais percepções podem contribuir para o desenvolvimento de sintomas de depressão e ansiedade e a rigidez destas crenças podem manter tais sintomas (Cohen e Mannarino, 2002; Heflin e Deblinger, 1996/1999; Runyon e Kenny, 2002; Valle e Silovsky, 2002). Dessa forma, a reestruturação de crenças disfuncionais das meninas, em ambos os grupos, foi prioridade na fase de psicoeducação, através do questionamento de evidências e da construção de explicaçôes alternativas.

A sexta sessão de psicoeducação explorou a relação entre pensamento, emoções e comportamentos, através do automonitoramento realizado como tarefa de casa, e mapeou as principais mudanças percebidas pelas meninas após o abuso sexual. Em cada grupo foi construído um painel com tais mudanças. As meninas destacaram: dificuldade para dormir, dificuldade de prestar atenção na aula, maior irritabilidade e brigas com outras pessoas, presença de sentimentos de medo, culpa, vergonha e raiva e isolamento social. Estas mudanças foram relatadas, também, por vítimas de abuso sexual em outros estudos (Azevedo, Guerra e Vaiciunas, 1997; Briere e Elliott, 2003; Habigzang e Caminha, 2004), o que confirma que tais alterações de comportamento possam ser fortes indicadores de violência sexual no processo de diagnóstico destes casos.

A sétima e última sessão de psicoeducação abordou as reações físicas que podem estar associadas aos pensamentos, emoçôes e comportamentos com as meninas em ambos os grupos. Juliana (11 anos) disse que sempre sentia falta de ar quando ficava nervosa. Luciana (11 anos) disse que em dia de prova sente dor de barriga. As meninas compreenderam com facilidade a relação entre os elementos emoções, pensamentos, comportamentos e reaçôes físicas abordados na psicoeducação. Com o objetivo de integrar esta compreensão, as terapeutas sugeriram que as meninas construíssem uma história em quadrinhos que retratasse uma situação-problema da semana. Depois que cada menina apresentou sua história ao grupo, as produçôes gráficas foram trocadas e cada uma recebeu como desafio pensar em uma estratégia alternativa para a resolução do problema apresentado na história. Por fim, cada menina recebeu sua história e avaliou a estratégia alternativa sugerida.

No segundo momento da sessão, as terapeutas trabalharam técnicas de relaxamento muscular e de respiração (Vera e Vila, 1996). Tais técnicas têm como objetivo auxiliar no controle da ansiedade. As meninas, em ambos os grupos, apresentaram, inicialmente, dificuldades para se concentrar na realização das técnicas, mas logo aprenderam a respiração diafragmática e relaxaram. No final do encontro, Luciana (11 anos) disse que usaria as técnicas aprendidas nos dias de prova na escola. Cristiane (nove anos) disse que tentaria fazê-las quando acorda à 
noite com pesadelos e tem dificuldade para dormir. As terapeutas incentivaram estas iniciativas e solicitaram que as meninas relatassem estas experiências nos próximos encontros.

Nas cinco sessões seguintes, desenvolveu-se com cada grupo a técnica de treino de inoculação do estresse (Deffenbacher, 1996). Esta técnica foi utilizada como dispositivo para ativar a memória traumática e detalhar os estímulos desencadeantes de lembranças intrusivas, possibilitando às participantes uma sensação de controle da intensidade das emoções associadas.

$\mathrm{Na}$ oitava e nona sessão as participantes apresentaram, de forma gradual, as situações abusivas experienciadas através do relato oral ou escrito. Alguns exemplos de relatos escritos das meninas:

Quando aconteceu o abuso foi na minha casa. Quando eu estava dormindo e o meu pai me chamou para mim passar roupa e quando eu vi ele estava mandando eu tirar a roupa. Quando aconteceu o abuso minha mãe estava trabalhando. Ele disse que se eu não tirava a roupa ele ia me queimar e me bater e eu fiquei com muito medo. O meu pai mandava eu tirar a roupa e ele tirou o pênis para fora para botar na minha vagina e eu fiquei com medo do meu pai. Até que um dia eu falei para minha melhor amiga e ela me ajudou muito. No dia em que eu contei ela ficou muito triste. Eu pensei que o meu pai não ia fazer isto comigo. E daí a minha amiga falou para a mãe dela e a mãe dela ligou para o conselho e daí o conselheiro tutelar foi lá na minha casa e daí conversou comigo e com a minha amiga que me ajudou. E daí o conselheiro deixou um papel para os pais irem no conselho conversar sobre o que aconteceu. A minha mãe ficou muito triste com o que aconteceu comigo. A minha mãe ficou muito triste porque ela nunca pensou que ia acontecer comigo!!! Eu não quero ver o meu pai nunca mais na minha vida. Eu estou com muita saudade da minha família e da minha amiga (Mariana, 11 anos).

$\mathrm{Na}$ nona sessão, os grupos ainda construíram seu "Botão de emergência", que reuniu estratégias para lidar com lembranças intrusivas sobre a violência sexual. Alguns exemplos de estratégias sugeridos nos grupos foram: brincar, assistir $\mathrm{TV}$, pensar no grupo, respirar fundo, conversar com amigos, conversar consigo mesma, cantar e dançar. Cada menina escreveu em um cartão amarelo as estratégias construídas e levou o botão de emergência para casa. Elisa (12 anos) disse que guardaria o seu dentro do estojo para utilizá-lo na aula. As meninas também quiseram construir um painel com o botão de emergência para enfeitar a sala de atendimento. 
$\mathrm{Na}$ décima e décima primeira sessões, o registro escrito das situações abusivas continuou a ser realizado e as meninas traziam a cada sessão mais detalhes. Depois de escrever sobre a situação, as meninas liam para o grupo. As meninas demonstravam apoio àquela que lia seu registro, segurando as mãos e oferecendo abraços. Juliana (11 anos), por exemplo, disse que foi interessante lembrar que o tio a abordou na cozinha, enquanto lavava louças, pois entendeu por que se sentia mal quando estava neste local da casa.

$\mathrm{Na}$ décima segunda sessão, foi realizado o jogo da memória para que as meninas compreendessem o funcionamento da memória e como é possível substituir lembranças de episódios negativos por outras de episódios positivos. Inicialmente, as terapeutas perguntaram para as meninas se elas já haviam ouvido falar sobre memória. Daniela (12 anos) imediatamente respondeu que a memória "está dentro da cabeça de cada pessoa e que guarda tudo o que já aconteceu na vida da gente". Aproveitando a idéia de Daniela, a coordenadora disse que a memória é como uma caixa cheia de gavetas que está na cabeça e que em cada gaveta está guardada uma situação já experienciada. Então, foi sugerido que as meninas fechassem os olhos e imaginassem a caixa da memória e depois escolhessem uma situação boa que estivesse guardada dentro de uma gaveta. Em seguida, solicitou que as meninas detalhassem tal situação em sua cabeça, pensando em seus detalhes. Após visualizar mentalmente a situação, cada menina desenhou o que havia pensado. Depois disto, as terapeutas pediram que as meninas fechassem novamente os olhos e abrissem a gaveta com a pior lembrança que tinham do abuso e pensassem na situação com detalhes. As meninas também desenharam ou escreveram a situação. Por fim, a terapeuta explicou que é possível substituir lembranças ruins por lembranças boas e treinou a substituição de imagens, solicitando que as meninas fechassem os olhos e pensassem na situação ruim, depois na boa e, assim, sucessivas vezes até que todas participantes conseguissem realizar a substituição. Luciana (11 anos) fazia com a mão um movimento na cabeça que simulava a abertura e o fechamento de gavetas.

Durante as sessões de treino de inoculação do estresse, a freqüência e a intensidade das lembranças traumáticas das meninas de ambos os grupos foram mapeadas e identificou-se que todas apresentaram redução deste sintoma. No início de cada sessão, as meninas comumente relatavam quantas vezes haviam lembrado do abuso e demonstravam a emoção que acompanhava estas lembranças ocorridas na semana entre os encontros com a equipe. Ao longo da intervenção, o número de lembranças foi diminuindo a cada nova sessão e as reações emocionais foram apresentadas de forma menos intensa. Além disso, as meninas relataram a utilização das estratégias aprendidas na grupoterapia em seu cotidiano, sendo que o 
botão de emergência e as gavetas da memória foram os recursos mencionados como mais explorados por elas. A redução da freqüência e intensidade de lembranças intrusivas e das reações emocionais através da ativação e reconstrução da memória traumática é um resultado também encontrado em outros estudos (Cohen, Mannarino e Rogal, 2001; Deffenbacher, 1996; Habigzang e Caminha, 2004). Esse processo possibilitou às meninas perceberem, no contexto seguro, que uma lembrança não significa que a situação está ocorrendo novamente. Assim foi possível reduzir o medo que tais lembranças geram para elas.

A última etapa da grupoterapia, denominada prevenção à recaída, constituída por oito sessões, teve como objetivos construir e fortalecer medidas de autoproteção, bem como retomar as técnicas e as estratégias aprendidas no contexto grupal para lidar com sintomas, pensamentos, emoções e comportamentos decorrentes do abuso sexual, em outras etapas da intervenção.

$\mathrm{Na}$ décima terceira sessão ocorreu a oficina sobre sexualidade em cada grupo, com o objetivo de esclarecer as dúvidas das meninas sobre mudanças no corpo decorrentes da puberdade, ficar, namorar, gravidez e doenças sexualmente transmissíveis. As meninas escreveram suas dúvidas em tiras de papel, que foram dobradas e colocadas em uma caixa. Depois a caixa passava de mão em mão enquanto tocava uma música e, quando esta parava, a menina que estava com a caixa tirava uma pergunta e o grupo discutia a resposta. Alguns exemplos de perguntas foram: "Como é ficar com um menino?", "Como as meninas engravidam?", "O que acontece quando ficamos 'mocinhas'?", "Por que as meninas se apaixonam pelos meninos e não tiram eles da cabeça quando estão apaixonadas?", "Por que tem homens que abusam de meninas e meninos?". As psicoterapeutas levaram figuras ilustrativas sobre o corpo humano e métodos anticoncepcionais para facilitar algumas explicaçôes. A questão do autocuidado foi explorada neste encontro, sendo que informações sobre métodos anticonceptivos e a utilização de preservativos para evitar doenças sexualmente transmissíveis foram salientadas. Os cuidados com a higiene também foram abordados na oficina, tendo sido lembrados pelas próprias meninas. Juliana (11 anos) disse que "é importante trocar o absorvente a cada duas horas para evitar fungos". Contou que aprendeu isso com sua mãe. Cristiane (nove anos) ensinou as meninas que "não se pode sentar no vaso sanitário de lugares públicos para não contrair doenças”. As meninas mostraramse muito atentas e participativas, compartilhando seus conhecimentos e experiências com seus grupos.

A décima quarta sessão abordou, em cada grupo, os direitos das crianças e adolescentes através da oficina sobre o Estatuto da Criança e do Adolescente. O objetivo desta oficina foi proporcionar às meninas o conhecimento da lei que as 
protege, dos órgãos a quem podem recorrer quando se sentirem em risco e, principalmente, dos direitos que possuem enquanto cidadãs. Dessa forma, foram discutidos a lei de proteção integral e os artigos relacionados com maus-tratos e pornografia infantil. Também foi conversado sobre os órgãos de proteção e a função de cada um deles. As meninas relataram suas experiências com o Conselho Tutelar e Juizado, contando sobre as audiências de que participaram, e construíram painéis com as informaçôes que consideraram importantes sobre o Estatuto.

$\mathrm{Na}$ décima sexta sessão foi realizada uma oficina de psicomotricidade com as meninas em ambos os grupos. A oficina constituiu-se como um espaço para brincadeiras que visavam à reintegração do esquema corporal, explorando sensações de prazer/desprazer, bem como a diferenciação entre toques abusivos e não-abusivos. Atividades tais como dança da cadeira, nó-humano, identificação por sinais e sons de animais, espelho, massa de modelar, estátua, entre outras, foram sugeridas e logo aceitas e desenvolvidas pelas participantes. As meninas demonstraram confiança entre si e divertiram-se muito durante as atividades. As participantes não apresentaram dificuldades de expressão corporal e a oficina foi finalizada com uma roda de dança.

A décima sétima sessão teve como objetivo retomar as estratégias para lidar com as lembranças abusivas e a elaboração de outras de enfrentamento para situações de risco. A identificação de comportamentos e de potenciais situações de risco é fundamental, devido aos altos índices de revitimizaçóes que ocorrem entre meninas vitimizadas sexualmente (Knell e Ruma, 1996/1999; Smith, 1993/1996). As terapeutas sugeriram que as meninas pensassem em situaçóes que consideravam de risco e escolhessem uma delas para ser dramatizada. As meninas rapidamente se organizaram, escolhendo uma situação, distribuindo os papéis e ensaiando a cena para ser apresentada e discutida com as terapeutas. Os grupos apresentaram boa capacidade de organização e realização da tarefa sugerida. As meninas da manhã dramatizaram uma cena na qual Andréia (11 anos) encontrava o tio que abusou dela na casa da avó. Na cena, Andréia ficava o tempo todo ao lado da avó e ligava para o pai vir buscá-la. O grupo da tarde dramatizou uma situação na qual Daniela (12 anos) estava sozinha em casa com o irmão menor e um estranho bateu à porta, dizendo que sua mãe havia pedido para arrumar a pia da cozinha que estava estragada. Daniela não abriu a porta e pediu à pessoa que retornasse mais tarde, depois que sua mãe chegasse em casa. Além de aprender a identificar situações de risco, as meninas receberam instruções sobre os locais onde podem solicitar ajuda e escolheram um adulto-referência para quem recorreriam nestas situações. A principal estratégia apontada pelas meninas foi contar imediatamente o que aconteceu para o adulto-referência, pois, segundo elas, "manter o 
segredo prolonga e piora a situação". As pessoas apontadas como referência pelas meninas foram os seus pais não-abusivos e as terapeutas. Elas, ainda, ressaltaram a importância de não andarem sozinhas em lugares pouco movimentados e não conversarem ou abrirem a porta de casa para estranhos. Com relação aos agressores, as participantes enfatizaram a importância de não ficar sozinhas com eles.

$\mathrm{Na}$ décima oitava sessão, todas as meninas estavam de férias escolares e solicitaram um encontro dos dois grupos para que pudessem se conhecer. A idéia partiu de Andréia (11 anos) e logo foi aceita pelas demais meninas. Fernanda (10 anos) deu a sugestão de levarem lanches e Priscila (13 anos) sugeriu que as meninas trouxessem CDs com as músicas de que gostavam. Juliana (11 anos) solicitou a presença das assistentes de pesquisa. $\mathrm{O}$ encontro foi uma festa com a participação das dez meninas e de toda a equipe de pesquisa. As meninas de cada grupo logo se apresentaram às do outro e propuseram às terapeutas realizarem as atividades que haviam sido feitas na oficina de psicomotricidade (dança, etc). Depois das brincadeiras, todas sentaram-se para lanchar, compartilhando os alimentos e bebidas que trouxeram. Durante o lanche, as meninas relataram como estavam utilizando as estratégias aprendidas na grupoterapia para controle da ansiedade e pensamentos intrusivos sobre o abuso.

A décima nona sessão abordou as expectativas das meninas, agora em seus grupos de origem, com relação ao futuro, através do jogo "máquina do tempo". O jogo sugeria que elas imaginassem a si mesmas no futuro, dentro do período de um ano, cinco, dez e trinta anos. As meninas apresentaram expectativas positivas para o futuro, salientando a importância de estudar para obter melhores condiçôes de trabalho, ter um bom emprego e casar e ter filhos. Muitas meninas falaram de suas expectativas sobre namoro e casamento e revelaram a importância do respeito nestas relaçôes. Algumas afirmaram que não querem "maridos que bebam e que batam nos filhos". Todas as meninas falaram sobre ter filhos e disseram que querem "trabalhar para que eles possam estudar, ter brinquedos e roupas boas". Também salientaram que querem "brincar com os filhos e levá-los para passear". Os projetos de vida das meninas revelaram o desejo de constituir uma família sem violência, na qual os pais sejam afetivos e protetivos com os filhos. Tais projetos para o futuro apontam a tentativa de superar os eventos negativos da vida. Expectativas de superação e idealização da família também foram encontradas no estudo realizado por De Antoni e Koller (2000) com meninas que sofreram violência intrafamiliar.

$\mathrm{Na}$ última sessão foi solicitada às meninas, de ambos os grupos, uma autoavaliação por escrito sobre a participação no grupo. Alguns exemplos destas autoavaliações estão apresentados a seguir: 
Muitas coisas mudaram em mim depois do grupo. Antes eu tinha muitos pesadelos com o meu dindo. Agora não tenho mais pesadelos e mesmo se tivesse usaria a gaveta da memória, que foi outra coisa legal que aprendi e que me faz esquecer de tudo que passei. Me sinto mais segura em relação ao meu tio. Aprendi com o grupo sobre gravidez, sexo e meu corpo. Antes do grupo olhava para o lado e lembrava do tio, tinha pesadelos horríveis e me sentia muito diferente de minhas amigas, mas agora, além de conhecer pessoas, fiz ótimas amizades (Andréia, 11 anos).

Antes do grupo eu era uma menina muito esquisita e falava coisas que não devia. Agora eu sou mais educada e não falo coisas que não devo falar. Faço mais coisas do que antes, brinco mais e falo coisas que as pessoas riem. Antes eu não queria nada com nada na escola, mas agora me acho uma menina muito esperta e quero ter uma profissão. Eu também lembrava bastante daquelas horríveis cenas, mas agora só lembro de estar de bem com a vida e não lembro mais daquelas cenas. Eu era uma menina muito mal atenciosa nas coisas de casa e das coisas de aula, mas quando comecei a vir ao grupo isso melhorou muito. Por todas estas coisas e por ter me ajudado bastante eu adoro o grupo (Mariana, 11 anos).

As auto-avaliações das participantes sugerem que a intervenção contribuiu para melhorar a auto-estima, as relações interpessoais e a retomada de atividades, tais como brincar e estudar, que haviam sido abandonadas em decorrência dos episódios de violência sexual. As meninas escreveram sobre as estratégias funcionais para lidar com a experiência de abuso e que elas têm utilizado no seu cotidiano. $\mathrm{O}$ grupo revelou seu papel significativo na rede de apoio social e afetiva das meninas, representando um espaço seguro para compartilhar experiências e sentimentos, bem como para aprender novas formas de lidar com situações adversas.

O término do processo grupoterápico foi experienciado com angústia por algumas participantes. As meninas expressaram sentir falta dos encontros do grupo. $\mathrm{Na}$ última sessão, algumas meninas trouxeram cartas de despedida para as outras e para as terapeutas. Na carta para a terapeuta, Andréia (11 anos) escreveu que "seria difícil ficar sem o grupo". Cristiane (nove anos) passou a apresentar pesadelos relacionados com o abuso diariamente nas três últimas semanas do grupo e no início de cada encontro informava às demais meninas o número de sessões restantes. Diante destas situações, foi definido que o grupo teria encontros com freqüência mensal durante um ano, uma vez que este passou a ocupar um importante papel na rede de apoio das participantes. Além disso, a equipe de pesquisa percebeu o compromisso ético assumido com as meninas e a importância de desligálas gradativamente da pesquisa. Dessa forma, também será possível acompanhar o desenvolvimento das meninas e investigar se os efeitos da intervenção serão manti- 
dos por um ano. A proposta do acompanhamento mensal foi aceita pelas participantes e pelos cuidadores. As meninas mantêm a assiduidade nos encontros mensais que vêm ocorrendo após o término da grupoterapia, nos quais relatam fatos ocorridos entre uma sessão e outra, propõem brincadeiras e trocam experiências.

\section{ConsideraÇÕes Finais}

O abuso sexual infantil intrafamiliar é um fenômeno complexo que envolve aspectos psicológicos, sociais e jurídicos, com altos índices de incidência, que pode ocasionar sérias alterações cognitivas, comportamentais e emocionais para a vítima. A terapia cognitiva-comportamental, desde suas primeiras formulações, tem articulado a pesquisa e a prática clínica (Beck e Alford, 1997/2000) e a avaliação de modalidades de tratamento tem apontado a eficácia/efetividade das técnicas cognitivas e comportamentais na reestruturação da memória traumática e redução de sintomas de ansiedade, depressão e transtorno do estresse pós-traumático identificados nas vítimas de abuso sexual. Além disso, o formato grupal tem apresentado resultados superiores no tratamento de crianças e adolescentes que experienciaram abuso sexual (Celano, Hazzard, Campbell e Lang, 2002; Cohen, Mannarino e Knudsen, 2005).

O modelo de grupoterapia cognitiva-comportamental descrito reduziu sintomas de depressão, ansiedade e transtorno do estresse pós-traumático, bem como modificou a percepção de diferença em relação aos pares, a culpa pela situação do abuso e pelas modificações na configuração familiar, identificadas na avaliação clínica inicial e durante o processo terapêutico. Outro aspecto positivo identificado foi a melhora no desempenho escolar, embora não testado, mas observado pelas participantes e seus cuidadores. As técnicas empregadas na etapa da psicoeducação foram importantes para a reestruturação de crenças disfuncionais. A psicoeducação e o treino de inoculação do estresse contribuíram para a redução de sintomas de transtorno do estresse pós-traumático, sendo que o jogo sobre a memória e o botão de emergência foram as estratégias que as meninas relataram adotar, quando apresentavam sintomas de revivência do trauma em seu cotidiano. A etapa final, de prevenção à recaída, promoveu a elaboração de estratégias de proteção através da identificação de situações de risco e das oficinas sobre sexualidade e sobre o Estatuto da Criança e do Adolescente. A oficina de psicomotricidade foi vivenciada com intensidade pelas participantes e foi a atividade mais lembrada por estas na avaliação final. Dessa forma, a reorganização das sessões, de acordo com objetivos e técnicas empregadas, qualificaram o modelo inicial proposto por Habigzang e Caminha (2004). 


\section{REFERÊNCIAS BIBLIOGRÁFICAS}

Astin, M. C. e Resick, P. A. (2002). Tratamento cognitivo-comportamental do transtorno de estresse pós-traumático. Em Caballo, V. E. (Ed.). Manual para o Tratamento CognitivoComportamental dos transtornos psicológicos (pp. 171-210). Porto Alegre: Artes Médicas.

Azevedo, M. A.; Guerra, V. N. A. e Vaiciunas, N. (1997). Incesto ordinário: a vitimização sexual doméstica da mulher-criança e suas conseqüências psicológicas. Em Azevedo, M. A. e Guerra, V. N. A. (Eds.). Infância e violência doméstica: fronteiras do conhecimento (pp. 195-209). São Paulo: Editora Cortez.

Beck, A. e Alford, B. A. (1997). O poder integrador da terapia cognitiva. (M. C. Monteiro, Trad.). Porto Alegre: Artes Médicas, 2000.

Briere, J. e Elliott, D. M. (2003). Prevalence and psychological sequelae of self-reported childhood physical and sexual abuse in a general population sample of men and women. Child Abuse e Neglect, 27, 1205-1222. London: Elsevier.

Calhoun, K. S. e Resick, P. A. (1993). Transtorno do estresse pós-traumático. Em Barlow, D. (Ed.), Manual clínico dos transtornos psicológicos (pp. 63-118; M. R. B. Osório, Trad.). Porto Alegre: Artes Médicas, 1999.

Celano, M.; Hazzard, A.; Campbell, S. K. e Lang, C. B. (2002). Attribution retraining with sexually abused children: Review of techniques. Child Maltreatment, 7 (1), 64-75. Thousand Oaks, CA, Sage.

Cohen, J. A. (2003). Treating acute posttraumatic reactions in children and adolescents. Society of Biological Psychiatry, 53, 827-833.

Cohen, J. A. e Mannarino, A. P. (2000). Predictors of treatment outcome in sexually abused children. Child Abuse e Neglect, 24 (7), 983-994. London: Elsevier.

. (2002). Addressing attributions in treating abused children. Child Maltreatment, 7 (1), 81-84. Thousand Oaks, CA, Sage.

Cohen, J. A; Mannarino, A. P. e Rogal, S. (2001). Treatment practices for childhood posttraumatic stress disorder. Child Abuse e Neglect, 25, 123-135. London: Elsevier.

Cohen, J A.; Mannarino, A. P. e Knudsen, K. (2005). Treating sexually abused children: one year follow-up of a randomized controlled trial. Child Abuse e Neglect, 29, 135145. London: Elsevier.

De Antoni, C. e Koller, S. H. (2000). A visão de família entre as adolescentes que sofreram violência intrafamiliar. Estudos de Psicologia, 5, 347-392.

Deblinger, E.; Stauffer, L. B. e Steer, R. A. (2001). Comparative efficacies of supportive and cognitive behavioral group therapies for young children who have been sexually abused and their nonoffending mothers. Child Maltreatment, 6 (4), 332-343. Thousand Oaks, CA, Sage. 
Deffenbacher, J. L. (1996). A inoculação do stress. Em Caballo, V. E. (Ed.). Manual para o Tratamento Cognitivo Comportamental dos transtornos psicológicos (pp. 557-580). São Paulo: Santos.

Estatuto da Criança e do Adolescente (1990). Diário Oficial da União. Lei Federal no 8.069, de 13 de julho de 1990. Brasília, Distrito Federal.

Furniss, T. (1993). Abuso sexual da criança: uma abordagem multidisciplinar. Porto Alegre: Artes Médicas.

Gabel, M. (1997). Crianças vitimas de abuso sexual. São Paulo: Summus.

Habigzang, L. F. e Caminha, R. M. (2004). Abuso sexual contra crianças e adolescentes: conceituação e intervenção clínica. São Paulo: Casa do Psicólogo.

Haugaard, J. J. (2003). Recognizing and treating uncommon behavioral and emotional disorders in children and adolescents who have been severely maltreated: Introduction. Child Maltreatment, 9 (2), 123-130. Thousand Oaks, CA, Sage.

Heflin, A. H. e Deblinger, E. (1996). Tratamento de um adolescente sobrevivente de abuso sexual na infância. Em Reinecke, M.; Dattilio, F. e Freeman, A. (Eds.). Terapia cognitiva com crianças e adolescentes: manual para a prática clínica (pp. 161-178; M. R. Hofmeister, Trad.). Porto Alegre: Artes Médicas, 1999.

Horowitz, L. A.; Putnam, F. W.; Noll, J. G. e Trickett, P. K. (1997). Factors affecting utilization of treatment services by sexually abused girls. Child Abuse e Neglect, 21 (1), 35-48. London: Elsevier.

Jonzon, E. e Lindblad, F. (2004). Disclosure, reactions and social support: Findings from a sample of adult victims of child sexual abuse. Child Maltreatment, 9 (2), 90-200. Thousand Oaks, CA, Sage.

Knell, S. M. e Ruma, C. D. (1996). Terapia do jogo com crianças sexualmente abusadas. Em Reinecke, M.; Dattilio, F. e Freeman, A. (Eds.). Terapia cognitiva com crianças e adolescentes: manual para a prática clínica (pp. 277-295; M. R. Hofmeister, Trad.). Porto Alegre: Artes Médicas, 1999.

Organização Mundial da Saúde. (1999). http://www.who.int/topics/child_abuse/en/, acessado em maio de 2005.

Rosenthal, S.; Feiring, C. e Taska, L. (2003). Emotional support and adjustment over a year's time following sexual abuse discovery. Child Abuse e Neglect, 27, 641-661. London: Elsevier.

Runyon, M. K. e Kenny, M. C. (2002). Relationship of atribucional style, depression and post trauma distress among children who suffered physical or sexual abuse. Child Maltreatment, 7 (3), 254-264. Thousand Oaks, CA, Sage.

Saywitz, K. J.; Mannarino, A. P.; Berliner, L. e Cohen, J. A. (2000). Treatment for sexually abused children and adolescents. American Psychologist, 55 (9), 1040-1049, Washington, DC: APA. 
Sheldon, D. R. (1993). Psicoterapia cognitivo-comportamental de grupo. Em Kaplan, H. I. e Sadock, B. J. (Eds.). Compêndio de psicoterapia de grupo (pp. 173-180; Abreu, J. O. A. e D. Batista, Trad.). Porto Alegre: Artes Médicas, 1996.

Smith, E. R. (1993). Psicoterapia de grupo com crianças sexualmente abusadas. Em Kaplan, H. I. e B. J. Sadock (Eds.). Compêndio de psicoterapia de grupo (pp. 441-457; Abreu, J. O. A. e Batista, D., Trad.). Porto Alegre: Artes Médicas, 1996.

Valle, A. L. e Silovsky, J. F. (2002). Attributions and adjustment following child sexual and physical abuse. Child Maltreatment, 7 (1), 9-24. Thousand Oaks, CA, Sage.

Vera, M. N. e Vila, J. (1996). Técnicas de relaxamento. Em Caballo, V. E. (Ed.). Manual de técnicas de terapia e modificação do comportamento (pp. 147-166). São Paulo: Santos.

\section{NoTAS}

1 Estudo financiado por CNPq, Edital Saúde Mental - Processo 554492/2005-9.

2 Foram atribuídos nomes fictícios às participantes para preservar a identidade das mesmas.

Recebido em 20 de julho de 2006 Aceito para publicação em 27 de novembro de 2006 